Supporting information for

\title{
Self-Catalyzed Sensitization of CuO Nanowires via Solvent-Free Click Reaction
}

\author{
Chuan He, ${ }^{1}$ Xuefen Cai, ${ }^{2,3}$ Su-Huai Wei, ${ }^{3}$ Anderson Janotti ${ }^{2}$ and Andrew V. Teplyakov ${ }^{1 *}$ \\ ${ }^{1}$ Department of Chemistry and Biochemistry, University of Delaware, Newark, DE 19716 \\ ${ }^{2}$ Department of Materials Science and Engineering, University of Delaware, Newark, \\ Delaware 19716, USA
}

${ }^{3}$ Beijing Computational Science Research Center, Beijing 100093, China

* Corresponding author, e-mail: andrewt@udel.edu

3 Pages

3 Figures

1 Table 

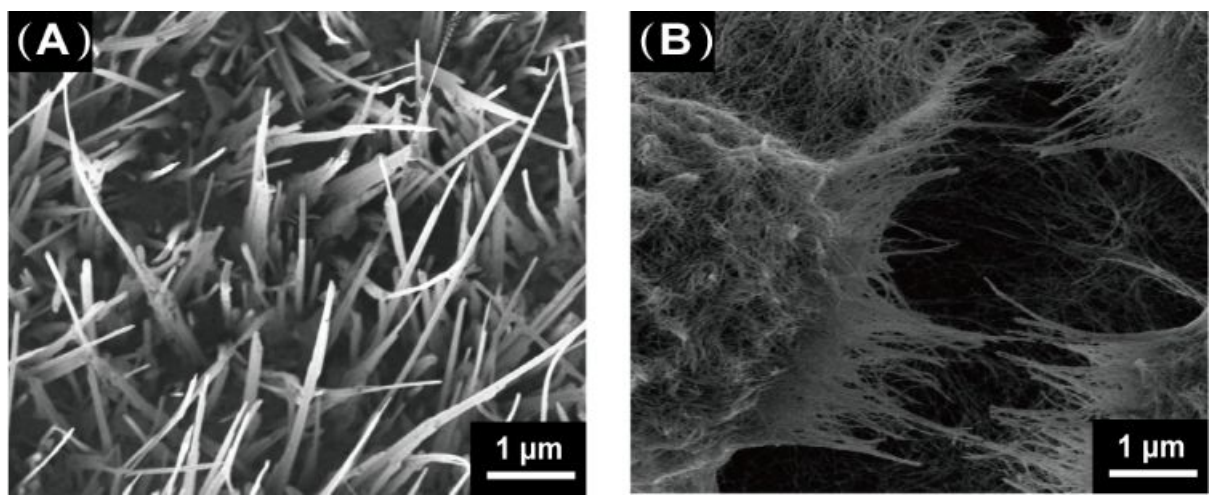

Figure S1 SEM images of the pristine $\mathrm{CuO}$ nanowires before (A) and after (B) being exposed to the diluted solution of prop-2-ynoic acid in THF for $1 \mathrm{~min}$.

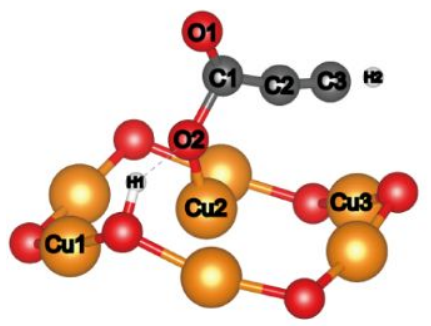

Monodentate model

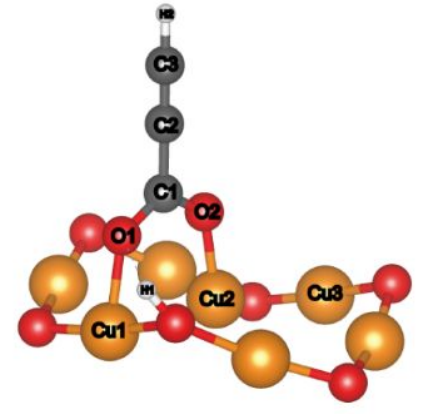

Bidentate model

Figure S2 The monodentate and bidentate models cut out from the periodic slab structures optimized with VASP.

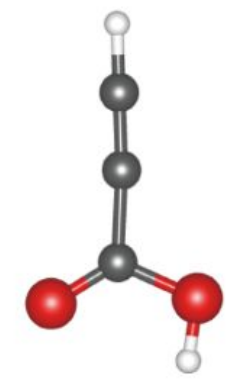

Prop-2-ynoic acid

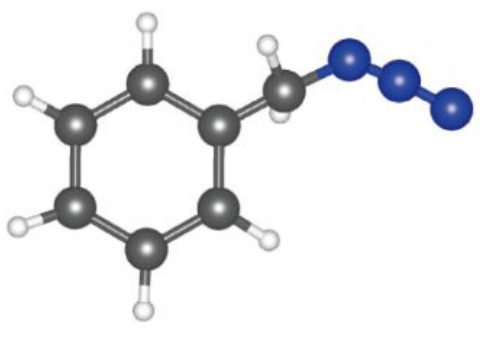

Benzyl azide

Figure S3 The predicted infrared spectra of prop-2-ynoic acid and benzyl azide (shown in figure S2) were obtained by Density functional theory (DFT) calculations using the Gaussian 09 Suite of programs with B3LYP functional and 6-311+G(d,p) basis sets ${ }^{1-3}$ for the comparison with FTIR spectroscopic measurements (Figure 2C). 


\begin{tabular}{|c|c|c|c|c|}
\hline Structure & $\begin{array}{c}\text { prop-2-ynoic } \\
\text { acid }\end{array}$ & $\begin{array}{c}\text { Monodentate } \\
\text { model }\end{array}$ & $\begin{array}{c}\text { Bidentate } \\
\text { model }\end{array}$ & $\begin{array}{l}\text { Benzyl azide } \\
\text { clicked model }\end{array}$ \\
\hline Side & & & & \\
\hline view & & & & \\
\hline Top & & - & & \\
\hline view & & & & \\
\hline $\mathrm{C} 1=\mathrm{O} 1$ & 1.22 & 1.35 & 1.28 & 1.36 \\
\hline C1-O2 & 1.32 & 1.42 & 1.35 & 1.45 \\
\hline O2-H1 & 0.98 & 1.94 & 1.75 & 1.97 \\
\hline $\mathrm{C} 1-\mathrm{C} 2$ & 1.39 & 1.34 & 1.44 & 1.47 \\
\hline $\mathrm{C} 2 \equiv \mathrm{C} 3$ & 1.21 & 1.17 & 1.21 & 1.38 \\
\hline C3-H1 & 1.07 & 1.21 & 1.07 & 1.08 \\
\hline O1-Cu1 & $\mathrm{N} / \mathrm{A}$ & 5.01 & 1.97 & 5.09 \\
\hline $\mathrm{O} 2-\mathrm{Cu} 2$ & $\mathrm{~N} / \mathrm{A}$ & 1.65 & 1.85 & 1.67 \\
\hline $\mathrm{C} 2-\mathrm{Cu} 3$ & N/A & 2.94 & 6.17 & 3.57 \\
\hline $\mathrm{C} 3-\mathrm{Cu} 3$ & $\mathrm{~N} / \mathrm{A}$ & 2.59 & 7.06 & 3.19 \\
\hline$\Delta \mathbf{E}^{*}$ & $\mathrm{~N} / \mathrm{A}$ & -1.57 & -0.55 & -2.16 \\
\hline
\end{tabular}

Table S1 Selected geometric parameters (in $\AA$ ) and calculated energies (in Ev) of the interested computational models. $\Delta \mathrm{E}$ represents $\Delta \mathrm{E}_{\mathrm{ads}}$ for the monodentate and bidentate models, and $\Delta \mathrm{E}_{\mathrm{r}}$ for the clicked model 